\title{
Electrical Imaging of a Shallow Free-Phase Stray Gas Plume from an Abandoned Exploration Well
}

\author{
Patrick A. Lagasca (iD, M. Cathryn Ryan (D), and Laurence R. Bentley \\ Department of Geoscience, University of Calgary, Calgary, Canada T2N 1N4 \\ Correspondence should be addressed to Patrick A. Lagasca; palagasc@ucalgary.ca
}

Received 22 July 2021; Accepted 30 September 2021; Published 22 November 2021

Academic Editor: Zhiyuan Wang

Copyright (c) 2021 Patrick A. Lagasca et al. This is an open access article distributed under the Creative Commons Attribution License, which permits unrestricted use, distribution, and reproduction in any medium, provided the original work is properly cited.

\begin{abstract}
Geophysical imaging of free-phase gas (FPG) within aquifers is an emerging method for understanding the mechanisms controlling stray gas migration from oil and gas wells. Crystal Geyser is an unsealed and partially cased well that transports stray $\mathrm{CO}_{2}$ gas to the shallow subsurface. Accumulations of subsurface $\mathrm{CO}_{2}$ FPG near Crystal Geyser have been inferred, but the actual location and dimensions remained unclear. Here, the subsurface FPG distribution surrounding Crystal Geyser was characterized by interpreting $2 \mathrm{D}$ electrical resistivity images with previous drilling records and field mapping. An approximately 70-metre-wide FPG plume was located laterally between Crystal Geyser's conduit and the Little Grand Wash Fault. The FPG plume spanned the vertical extent of approximately 20 to 55 metres below the ground surface, located within the Slick Rock Member sandstone with the relatively low permeability Earthy Member silty sandstone acting as a caprock. The FPG plume was identified from an anomalously high resistivity zone within the Slick Rock Member that was not caused by lateral lithofacies changes or fault displacement. The conceptual FPG migration pathways beneath Crystal Geyser are presented, based on the interpreted FPG distribution from the electrical resistivity images combined with previous site characterization and the principles of buoyant FPG migration. FPG accumulates within the Slick Rock Member by buoyant up-dip migration beneath siltstone capillary barriers of the Earthy Member. FPG leaks to the ground surface within high permeability preferential pathways along the Little Grand Wash Fault and the conduit of Crystal Geyser.
\end{abstract}

\section{Introduction}

Stray (or "fugitive") gas release is the upward escape of subsurface gases (hydrocarbon or non-hydrocarbon), often induced by oil and gas development [1]. A primary pathway for stray gas migration is oil and gas wells with compromised cement seals or casings $[1,2]$. Stray gas can impact the groundwater quality of shallow aquifers and contribute to atmosphere emissions because of the preferential transport of buoyant free-phase gas (FPG) within high permeability pathways [1], such as faults, fractures, and wellbores [1, 3, 4]. FPG is inclined to migrate vertically through large, connected pore spaces (i.e., high permeability pathways) because of relatively low capillary entry pressures [1]. Free-phase stray gas migrating along preferential pathways can spread laterally into the surrounding aquifers [1], displacing groundwater from the pore spaces with FPG. For example, a vertical migration pathway obstructed by a relatively low permeability layer (or "capillary barrier") will preferentially divert FPG along a lateral pathway, beneath the layer [5]. FPG can become trapped depending on the integrity and orientation of the capillary barrier $[1,5]$. Trapped FPG accumulations can extend over widespread lateral areas in aquifers that are overlain by continuous confining units [1].

There is a lack of peer-reviewed field-based hydrogeology studies related to stray gas release mainly due to the inherent difficulties in identifying stray gas sources and pathways [2]. For example, the tendency for preferential FPG pathways to be oriented vertically makes them challenging to characterize with groundwater monitoring wells. Furthermore, wellbores themselves can alter FPG pathways. The buoyant properties of FPG, caused by its low density 
compared to water, can cause FPG to migrate in complex pathways irrespective of groundwater flow [1]. In response to these FPG characterization difficulties and the lack of observation-supported studies, recent studies have employed geophysical [6-8] or light transmission [9] methods to image the migration pathways of free methane gas from a controlled injection point, within sandy aquifers. These studies observed lateral spreading of free-phase methane that was strongly controlled by layers with relatively low permeability-even by thin lenses with slightly finer grain size. Free-phase methane was observed to migrate laterally further than expected by groundwater advection alone [6, $7]$, and FPG plumes were temporally persistent below capillary barriers [6-9].

Crystal Geyser, an abandoned exploration well and a $\mathrm{CO}_{2}$-driven geyser, presents an opportunity to implement field-based geophysical imaging of stray subsurface FPG surrounding an unsealed borehole and fault network. At this time, no published research was found of geophysical imaging of FPG at an actual well (i.e., all related studies were controlled injection sites). The Crystal Geyser study site is auspicious for a geophysical imaging investigation because of the supported existence of subsurface FPG, the extraordinary magnitude of FPG flux emitted from the borehole and ground surface, and the well-characterized site hydrogeology. From captured geophysical images, the FPG migration behaviour will be interpreted by applying the current understanding of FPG migration mechanisms, for example, in the studies mentioned above.

This study utilizes electrical resistivity tomography (ERT) to image the near-surface geology and subsurface FPG distribution around Crystal Geyser. ERT has the demonstrable ability to capture bulk resistivity increases in a porous medium caused by the replacement of conductive pore fluids with FPG, e.g., [7, 8, 10, 11]. In this study, tomogram image interpretation of Crystal Geyser and the surrounding subsurface was constrained by previous data: the borehole log of Crystal Geyser (Ruby 1-X) [12] and a nearby scientific exploration well (CO2W55) [13], drilling reports of pressurized FPG release $[12,13]$, geological mapping [3, $14,15]$, and ground surface free-phase $\mathrm{CO}_{2}$ gas flux measurements [16]. To evaluate the reliability of geophysical interpretations, a depth of investigation analysis [17] was conducted, and tomogram data were compared to separate resistivity estimates calculated with Archie's Law Equation [18].

1.1. Geological Setting. Crystal Geyser, located in Utah, USA (Figure 1), is an abandoned exploration well that remains an active cold-water geyser, discharging water and stray $\mathrm{CO}_{2}$ gas. In 1935, Crystal Geyser was drilled as petroleum exploration well Ruby 1-X within the Paradox Basin, a region comprised of several structurally trapped natural reservoirs of $\mathrm{CO}_{2}$ [19]. The borehole was drilled into the hinge of the Green River Anticline, a north-plunging fold that is cross-cut by the Little Grand Wash Fault (Figure 1) [13]. Free-phase and supercritical $\mathrm{CO}_{2}$ are believed to accumulate beneath the fine-grained sedimentary strata in the Green River Anticline [13]. In 1936, Ruby 1-X was aban- doned middrilling after a blowout, which continued to erupt as high as $45 \mathrm{~m}$ every nine hours [20]. Crystal Geyser transports mixed groundwater with free- and dissolved-phase $\mathrm{CO}_{2}$ to the surface [21]. Ongoing eruptions continue, emitting nearly pure $\mathrm{CO}_{2}$ into the atmosphere at an estimated rate of $1.1 \times 10^{7} \mathrm{~kg}$ per year [19]. The borehole of Crystal Geyser has a total depth of $801 \mathrm{~m}$ [12] with a casing installed

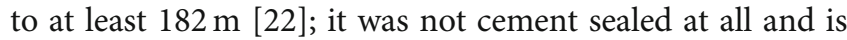
estimated to be transmissive to a depth of approximately $300 \mathrm{~m}$ (i.e., the bottom of the Navajo Formation) [13]. Erupted water (or "effluent" [21]) is primarily a mixture of groundwater from the intersected Entrada and Navajo aquifers (Figure 2) [21]. The brackish effluent has an electrical conductivity of 14.5 to $19.0 \mathrm{mS} / \mathrm{cm} \mathrm{[23]} \mathrm{and} \mathrm{a} \mathrm{pH}$ of 6.3 to 6.5 [13] (due to carbonation), potentially causing well casing corrosion over time.

The presence of subsurface FPG near Crystal Geyser is well-supported, and near-surface FPG accumulations may exist. The broad spatiotemporal distribution of subsurface $\mathrm{CO}_{2}$ fluids (free-phase, dissolved-phase, and supercriticalphase) and surface free-phase $\mathrm{CO}_{2}$ efflux is well-documented along the Green River Anticline and intersecting fault zones $[3,13,14,16,24-26]$. "Shows" of FPG were observed in the Crystal Geyser drilling log at multiple depths, as shallow as $39 \mathrm{~m}[12,20]$. "Pockets of free $\mathrm{CO}_{2}$ gas," at depths of 50 and $140 \mathrm{~m}$ within the Entrada Formation (Figure 2), were encountered during the scientific drilling of CO2W55 (location indicated in Figure 1) [13]. Furthermore, a FPG accumulation within the Entrada Formation was inferred to be the source of erupted gas during Crystal Geyser's most powerful (or "major" [21]) eruptions because the $\mathrm{CO}_{2}$ discharge and duration were too large/lengthy to be solely supplied by degassing inside the well conduit [27]. Consequently, numerical modelling studies simulated the large-scale lateral spreading and development of FPG plumes beneath low permeability strata in the Green River Anticline [26, 28, 29]. Despite the few drilling observations and modelling efforts of FPG, the actual location and greater spatial extent of such speculated FPG accumulations remain uncertain.

Figure 3 illustrates the exposed geology in the study area. Site photos are included as Supplementary Figures S1S3. Crystal Geyser was drilled into the footwall of the Little Grand Wash Fault (Figure 3) [14]. The exposed stratigraphic unit of the footwall is the Earthy Member of the Entrada Formation (Figure 3) [14]. The outcropping Earthy Member is red-brown siltstone to silty sandstone with nodular to irregular bedding $[15,26]$. The pale brown Curtis Formation overlies the Earthy Member with a local dip of $9^{\circ} \mathrm{N}$ (Figure 3) [3]. The sharp contact between the Earthy Member and Curtis Formation [15] is observable in the outcrop (Figure 3 and Figure S3).

Between Crystal Geyser and the Green River, ochrecoloured modern travertine actively precipitates from the drainage of effluent from Crystal Geyser (Figure 3). The modern travertine is thinly laminated and highly porous, covering a semicircular area with a maximum width of $85 \mathrm{~m}$ [30]. The modern travertine partially covers the northern edge of a paleotravertine composed of inactive porous travertine underlain by aragonite veins (Figure 3). In contrast to the modern 

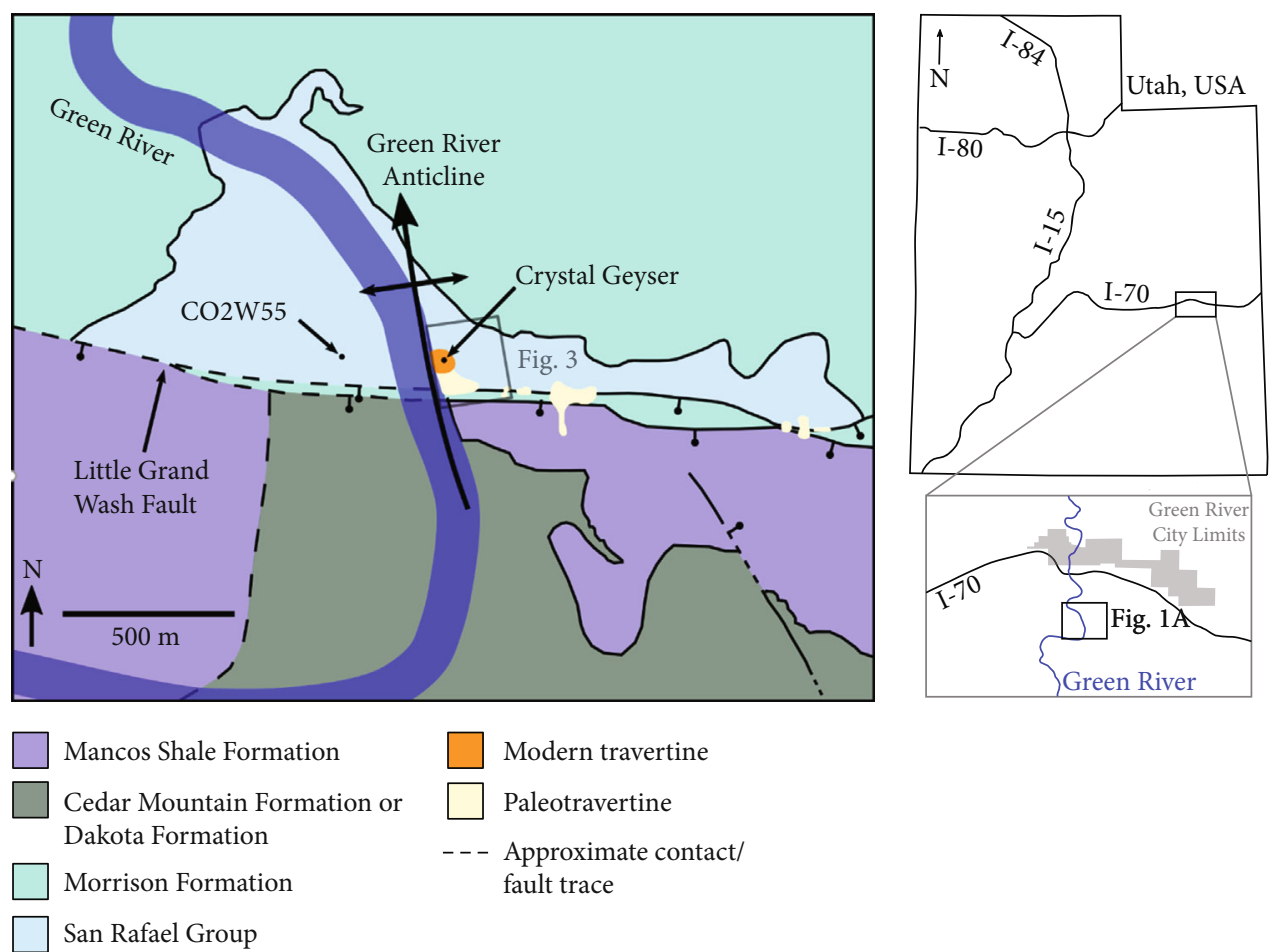

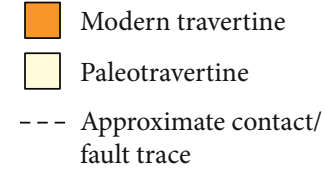

(a) (b)

Figure 1: (a) Geological map of the extended area surrounding the study site and (b) map of Utah, USA. (a) Simplified geological map of the Paradox Basin, near Crystal Geyser (Emery and Grand Counties). The W-E trending Little Grand Wash Fault cross-cuts the north-plunging Green River Anticline. Crystal Geyser is located on the hinge of the Green River Anticline. The Little Grand Wash Fault has two primary fault traces near Crystal Geyser. Modern and paleotravertine mounds that drape over the fault traces are shown, as is the area included in Figure 3 (grey box). Scientific exploration well CO2W55 is located 285 west of Crystal Geyser [13]. Modified from Doelling et al. [15] and Dockrill and Shipton [3]. (b) The location of the study site within the state of Utah, including Interstate Highways. The area of (a) is indicated within the inset map. Modified from Google Earth map data (accessed May 28, 2021).

deposits, the paleotravertine is predominantly composed of a series of thick (decimetre-scale) bedding-parallel aragonite veins [24] These veins are nonporous, brittle, and extremely dense [30]. A three-metre-thick exposure of the aragonite veins is located along the bank of the Green River, $40 \mathrm{~m}$ west of the ERT line (Figure 3) $[14,30]$.

The northern and southern primary splays of the Little Grand Wash Fault are located near the topographic upland at the southern area of the study site (near " $A$ "; Figure 3 ). At this location, the stratigraphic offset across both splays is $260 \mathrm{~m}$, which is the maximum throw for the entire extent of the fault [3]. Furthermore, the paleotravertine drapes over both primary fault splays (Figure 3) [3, 14]. On the surface, the paleotravertine is exposed or covered by thin layers of soil (Figure S2). Additionally, a secondary fault splay trace of the Little Grand Wash Fault is approximately $40 \mathrm{~m}$ north of Crystal Geyser [13]; the fracture zone was recovered in core intersecting the Carmel Formation (150 m depth; [13]. The dip-slip displacement at the secondary fault splay is minimal, as only $\mathrm{mm}$ - to $\mathrm{cm}$-scale normal offsets were observed in the core [13]. Near the fault splay trace, there is no observable displacement at the exposed contact between the Earthy Member and Curtis Formation (Figure S3).

\section{Materials and Methods}

2.1. Geophysical Methods. Direct current ERT surveys were completed over a single 2D transect oriented parallel to the channel of the Green River (NW to SE; Figure 3). Eighty electrodes with spacings of 3.0 and $1.5 \mathrm{~m}$ were used, resulting in total survey line lengths of 240 and $120 \mathrm{~m}$, respectively $\left(A-A^{\prime}\right.$ and $B-B^{\prime}$, Figure 3$)$. The transects were placed with Crystal Geyser at their centre, offset orthogonally by five metres to minimize unwanted electrical conductance from the metal casing. Measured resistance data were collected with a 12-channel ABEM Terrameter LS2 resistivity metre utilizing the dipole-dipole and gradient array types [31]. The electrodes were coated in a saltwater-bentonite mixture, then inserted into the ground to a depth of approximately $20 \mathrm{~cm}$. On exposed travertine, pilot holes were drilled before electrode insertion.

The ERT surveys capture subsurface conditions during Crystal Geyser's noneruptive (or "recharge") period, which follows the largest (or "major") eruption period (see [21] for a description of the entire geyser eruption interval). At the onset of the recharge period, the borehole water level is its lowest elevation, then slowly rises. No effluent was ejected onto the surface, and minor bubbling is observed within the 

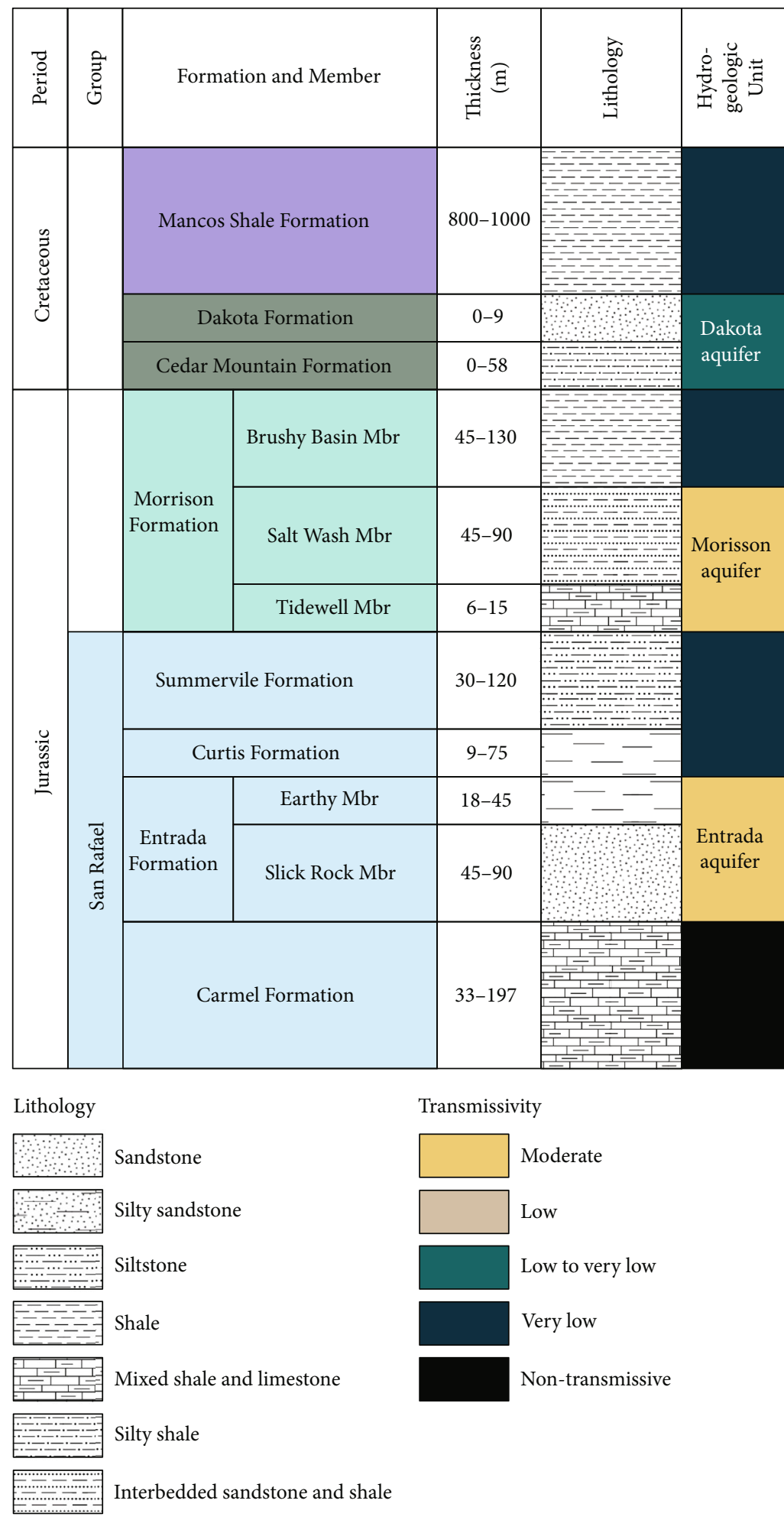

Figure 2: Stratigraphic section of the Cretaceous and Jurassic units of this study, including the range of thickness, lithologies, and hydrogeologic units. The colour of the stratigraphic units corresponds to the units of Figure 1, and the units in bold font are exposed at the study site (see Figure 3). The original stratigraphic section was modified from Doelling et al. [15]. Hydrogeologic classification was modified from Kampman et al. [13].

borehole. The travertine surface near the geyser was damp from the preceding major eruption period, but no pooling of water around the electrodes was observed. A dipole- dipole survey immediately followed a gradient survey to provide pairs of comparable sections that capture approximately the same subsurface conditions. 


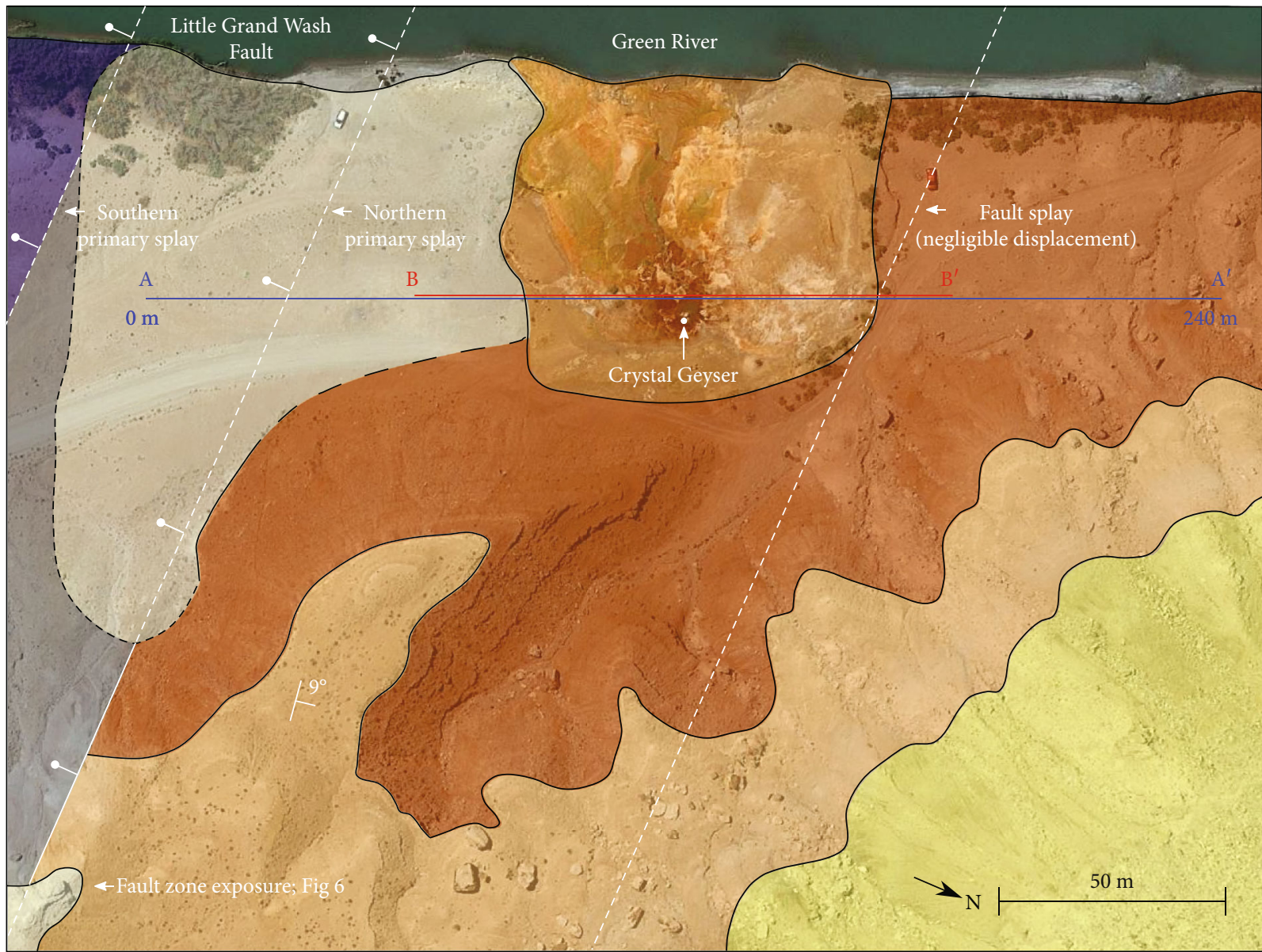

ERT line location:

A $\quad \mathrm{A}^{\prime} 3.0$ m electrode spacing

B $\quad \mathrm{B}^{\prime} \quad 1.5 \mathrm{~m}$ electrode spacing
Modern travertine

Paleotravertine

Brushy Basin Member

Mancos Shale Formation
Earthy Entrada Member

Curtis Formation

Summerville Formation or

Morrison Formation

(Tidewell or Salt Wash Member)

FIGURE 3: Site map of ERT survey lines with exposed geological units and fault traces (dashed white lines). The area is shown in the larger map of Figure 1(a). The lines overlie the northern primary splay of the Little Grand Wash Fault and another fault splay. Electrode spacings of $3.0\left(A-A^{\prime}\right)$ and $1.5 \mathrm{~m}\left(B-B^{\prime}\right)$ were used for surveys, resulting in total survey lengths of 240 and $120 \mathrm{~m}$, respectively. For all surveys, Crystal Geyser was located at the centre of the line, offset orthogonally by $5 \mathrm{~m}$. The location of Figure 6 is indicated. The strike and dip measurement of the Curtis Formation is from Dockrill and Shipton [3]. Mapping of the stratigraphic units and travertines is from Shipton et al. [14] and Dockrill and Shipton [3], modified using the satellite image (Google Earth imagery date: August 24, 2019). The fault splay position was identified by Kampman et al. [13].

2.1.1. Inversion. The program Res2Dinv (version 4.9.11) [32] was used to construct $2 \mathrm{D}$ resistivity tomograms by inversion of the collected field data. Significant changes in resistivity were expected across sharp lithological and structural boundaries (e.g., travertine basal surfaces and fault planes). Therefore, an L1 norm data constraint and an L1 norm model constraint were implemented (also known as "robust" data and model constraints) [32]. The L1 data norm produces more reasonable results for substantial differences in measured resistances [32]. The L1 data norm minimizes the absolute difference (instead of the L2 norm, which uses the square of difference) between measured and calculated apparent resistivity values until the smoothness-constrained objective function is minimized [32]. Furthermore, the L1 model norm produces an image with sharper resistivity contrasts than the L2 norm [32], which better resembles the exposed sharp contacts observed at the study site.

Before inversion, all negative measured resistances were deleted from the raw field-collected data. Erroneous apparent resistivity values with considerable contrasts compared to adjacent data were deleted, which were likely caused by electrode relay failure, poor surface conductance, or shorting 
across the surface because of wet ground conditions [32]. Additionally, apparent resistivity outliers were removed that had a large data misfit between measured and calculated apparent resistivity values.

After inversion, the tomograms were constructed by importing the recovered resistivity data (or referred to here as "tomogram resistivity") into the contouring software Surfer ${ }^{\circledR}$ from Golden Software, LLC (version 20.1.195; http://www.goldensoftware.com). Resistivity contours were created with the triangulation gridding method. In this study, the $5^{\text {th }}$ to $95^{\text {th }}$ resistivity percentile data is presented as the "resistivity range" for each interpreted tomogram unit.

2.1.2. Depth of Investigation Analysis. To delineate "interpretable" areas within tomograms that are representative of subsurface physical properties, the depth of investigation (DOI) algorithm by Oldenburg and Li [17] was implemented. DOI is defined as "the depth below which surface data are insensitive to the physical property of the earth" [17]. Within a first-order estimate, tomogram resistivities above the DOI are reliable estimates of the true resistivity of the porous media, and resistivity bodies represent the morphology of geological structures [17]. In contrast, tomogram resistivity values below the DOI approach a constant value (i.e., become less reliable) because the field-collected data are less sensitive to the true subsurface resistivity:

$$
R(x, z)=\frac{m_{1}(x, z)-m_{2}(x, z)}{m_{1 r}-m_{2 r}}=\frac{m_{1}(x, z)-m_{2}(x, z)}{0.1 \rho_{a, \text { average }}-10 \rho_{a, \text { average }}}
$$

Equation (1) is the DOI index $(R)$ [17]. $m_{1}(x, z)$ and $m_{2}$ $(x, z)$ are the logarithms of recovered resistivities (twodimensional matrices) resulting from two different inversions which used initial reference resistivity values $m_{1 r}$ and $m_{2 r}$, respectively. $m_{1 r}$ and $m_{2 r}$ are 0.1 and 10 times the logarithm of average field-measured apparent resistivity $\left(\rho_{a}\right)$ (Equation (1)) [32]. Before any minimization iteration, all elements of the two resistivity matrices are $m_{1 r}$ and $m_{2 r}$. After inversion, $R$ is calculated for every corresponding element between the two recovered resistivity matrices. Within a finalized tomogram, a reliable recovered resistivity value will have an $R$ value that approaches zero because the two different inversions produce nearly the same resistivities, despite having different initial values (Equation (1)). In contrast, a recovered resistivity value that is insensitive to the true subsurface resistivity will have an $R$ value that approaches one (unity), and the resistivity value approaches the initial reference resistivity.

After calculating $R$, all values were scaled using Equation (2) $[17,33] . R_{M}$ is the maximum DOI value that was calculated from Equation (1) (Equation (2)). Scaling the $R$ values ensures that $R$ approaches unity at depth [17] and that the results are comparable between different array types:

$$
R(x, z)=\frac{m_{1}(x, z)-m_{2}(x, z)}{R_{M}\left(0.1 \rho_{a, \text { average }}-10 \rho_{a, \text { average }}\right)} .
$$

In this study, a representative DOI was chosen where the $R$ values increase rapidly, which commonly occurs at $R=0.1$ to $0.2[17,33]$. Therefore, tomogram resistivities with an $R<0.1$ to 0.2 are above the DOI and are considered reliable.

2.1.3. Archie's Law Equation Resistivity Comparisons. In the tomogram results, high resistivity anomalies were interpreted as sections of porous media with elevated FPG fraction in the pore space (see Section 3.2). To provide a qualitative evaluation of this interpretation, anomalous tomogram resistivities were compared to separate resistivity estimates calculated with Archie's Law Equation. The Archie Equation for bulk resistivity $\left(\rho_{\mathrm{b}}\right)$ of a porous medium, containing FPG and groundwater in the pores, is [18]

$$
\rho_{\mathrm{b}}=\left(\sigma_{\mathrm{w}} \varphi_{\mathrm{int}}^{m} S_{\mathrm{w}}^{n}\right)^{-1}
$$

Equation (3) assumes that the solid (rock) phase is an insulator. Bulk resistivity is determined by the product of the conductivity of groundwater $\left(\sigma_{\mathrm{w}}\right)$, interconnected porosity $\left(\varphi_{\text {int }}\right)$, and water saturation $\left(S_{\mathrm{w}}\right)[18] . S_{\mathrm{w}}$ is water saturation-the fraction of porosity that is occupied by groundwater, where the remaining porosity is occupied by FPG (i.e., $\left.S_{\mathrm{w}}+S_{\mathrm{g}}=1\right)$ ). $m$ is the porosity exponent, and $n$ is the saturation exponent [18]. For consolidated sedimentary rocks, $m$ and $n$ are equal to 2 [18].

For $\sigma_{\mathrm{w}}$ values in Equation (1), a Solinst LTC Levelogger Edge [34] transducer was installed within Crystal Geyser's conduit at a depth of $8.5 \mathrm{~m}$ below the ground surface (Figure S8). The transducer measured water electrical conductivity $\left(\sigma_{\mathrm{w}}\right)$ (and hydrostatic pressure and temperature) every minute for the entire duration of ERT surveys. Additionally, the placement of the transducer and the condition of the geyser casing/conduit were inspected with a Well-Vu underwater camera [35].

2.2. Geological Interpretation. To correlate tomogram resistivity bodies with lithology, the tomogram results were compared to existing borehole records and geological maps. The original cable tool drill cutting descriptions of Crystal Geyser/Ruby 1-X [12] were separated into geological units based on established lithology descriptions of the travertines and the Earthy and Slick Rock Members of the Entrada Formation [13, 15, 26, 30]. The Crystal Geyser drilling log was also compared to the recovered core log and lithological interpretations of scientific exploration well CO2W55, drilled by Kampman et al. [13]. Crystal Geyser and CO2W55 have similar current-day ground surface elevation $(\sim 1238 \mathrm{~m}$ above sea level) and are located $285 \mathrm{~m}$ apart (Figure 1) [13], and there is no known structural displacement between the wells. Therefore, the well logs have approximately corresponding depths, and the geological units were compared directly. Field mapping was conducted along the ERT transects to identify exposed units. Additionally, geological mapping of stratigraphic units, structural features, and travertine mounds from previous studies was utilized [3, 13-15]. 


\section{Results and Discussion}

3.1. Crystal Geyser Borehole Log Interpretation. The interpreted drilling log of Crystal Geyser is shown in Figure 4. At the time of drilling in 1935, the ochre-coloured modern travertine was not yet deposited (as Crystal Geyser did not exist). The modern travertine is not on the Ruby 1-X drilling log; however, it is estimated to be "no more than a few metres thick" based on shallow cores $(<40 \mathrm{~cm}$ depth) [30].

The first $4.6 \mathrm{~m}$ (15ft) depth of the Ruby 1-X drilling log was described as "porous rock," which corresponds to porous travertine extracted in the core by Barth [30]. This older porous travertine was described as grey and porous with detrital material and may have been actively deposited from springs shortly before the drilling of Ruby 1-X [30]. From 4.6 to $8.8 \mathrm{~m}$ (29ft), "white rock" and "hard calcite" cuttings were encountered, which correspond to the white nonporous aragonite veins of the paleotravertine, located south of the Geyser. The paleotravertine mound is laterally continuous at depth and underlies the older porous travertine (and modern travertine) near Crystal Geyser.

An interbedded series of "red sandstone" and "red shale" between 8.8 and $32.6 \mathrm{~m} \mathrm{(107ft)}$ is interpreted to be the redbrown Earthy Member silty sandstone. At $38.1 \mathrm{~m}$ (125 ft) and below, thick metre-scale beds of "hard white sand" and "white sandstone" were observed, which are diagnostic of the bleached aeolian cross-bedded sandstones of the Slick Rock Member [15, 26]. Sandstone bleaching occurs from the acid-reductive dissolution of sand grain hematite coatings by $\mathrm{CO}_{2}$-charged groundwater, commonly observed for the Entrada Formation's transmissive sections [3, 13]. The transmissive Slick Rock Member (fine- to coarse-grained sand) [13] shows strong preferential bleaching, whereas the low transmissivity silty Earthy Member retains its redbrown colour [26]. The Earthy Member has a sharp subhorizontal basal contact with the Slick Rock Member $[13,26]$. This sharp lithological contact and the iron-leached front (indicated by colour change) coincide within a few metres, to a maximum vertical separation of $4 \mathrm{~m}$ [26]. The deepest occurrence of "red sandstone" occurs at $32.6 \mathrm{~m}$, and the shallowest occurrence of "white sandstone" occurs at $38.1 \mathrm{~m}$. Therefore, the lithological contact is interpreted to occur at a depth between 32.6 and $38.1 \mathrm{~m}$ (Figure 4). In comparison, Kampman et al. [13] recovered red-brown siltstone in the CO2W55 log from the surface to $35 \mathrm{~m}$, which they also interpreted as the Earthy Member; at 35 m, the Earthy Member has sharp contact with the bleached and cross-bedded Slick Rock Member [13]. The Slick Rock Member base (or the base of the Entrada Formation) was observed at $150 \mathrm{~m}$ in CO2W55 [13]; similarly, the Ruby 1-X original drilling record noted the base at $148 \mathrm{~m}$ [12] (Figure 4).

\subsection{Tomogram Resistivity Distribution and Interpretation.} The colocated resistivity tomograms of the 3.0 and $1.5 \mathrm{~m}$ electrode spacing surveys are shown in Figure 5. A summary of resistivity ranges and estimated apparent vertical thicknesses for each interpreted tomogram unit is shown in Table 1 . The DOI index $(R)$ contours were overlain onto the tomograms, which increase in white opacity with increasing $R$ values (Figure 5). Additionally, the interpreted borehole log of Figure 5 was placed at the location of Crystal Geyser. The depth alignment of the borehole log may differ by a few metres because the modern travertine was not deposited at the time of drilling (Section 3.1); however, this depth difference is minimal at the tomogram scale.

Only dipole-dipole array tomograms are presented because they had a greater DOI relative to the gradient survey tomograms, and the overall resistivity distribution between the array types was congruent. Additional gradient and dipole-dipole array tomograms are presented in Figure S5. The continuous transducer time series data, overlain with survey data collection duration for all tomograms, is shown in Figure S6. Each survey had approximately 1400 resistance measurements and an average data collection time of 42 minutes (Figure S6). Eight to 33 erroneous or outlier resistivity points were removed from each tomogram during preinversion processing (average of 17). All inversions automatically converged at the fourth minimization iteration [32], with the absolute error ranging from $2.5 \%$ to $4.7 \%$.

The paleotravertine and "porous travertine" (including the porous modern travertine and the older porous travertine, see Section 3.1) form well-defined and discrete resistivity bodies with depths consistent with the interpreted borehole log. Towards the southern topographic upland (near " $A$ "; Figure 3), the paleotravertine has a very high resistivity, typically greater than $200 \Omega \mathrm{m}$, to a maximum of $4000 \Omega \mathrm{m}$. In this area, the paleotravertine is approximately eight to nine $m$ thick with a sharp resistivity contrast with the underlying unit (Figure 5(a)). This estimated thickness is consistent with the paleotravertine outcrop along the Green River, which had a minimum/exposed thickness of three $\mathrm{m}$.

The porous travertine mound has a moderate resistivity varying from 50 to $180 \Omega \mathrm{m}$, which is considerably lower than the surrounding/underlying paleotravertine. The porous travertine has a maximum thickness of approximately five $m$ near Crystal Geyser and is less than one $m$ thick at the ground surface contact with the paleotravertine (Table 1; Figure 5). In the porous travertine, resistivity is further segregated into small discrete zones of high and low resistivity (Figure 5). These resistivity irregularities may represent a network of interconnected caves alternately filled with water and/or FPG during imaging (illustrated in Figure S8). The paleotravertine located beneath the porous travertine mound demonstrates a sharp contrast in resistivity but has reduced resistivity compared to the paleotravertine near the northern primary fault splay (Figure 5(a)). These reduced resistivities vary from 130 to $200 \Omega \mathrm{m}$ and are likely caused by an elevated fraction of brackish effluent in the pore space because the area surrounds Crystal Geyser. The upward/lateral penetration and downward infiltration of effluent likely lower the paleotravertine's resistivity. Additionally, the basal surfaces of the paleotravertine and porous travertine demonstrate an undulatory morphology that mimics the current-day topography. These undulatory basal surfaces may represent paleoground surfaces from periods of non-deposition.

On the southern topographic upland $70 \mathrm{~m}$ south of Crystal Geyser, a narrow, relatively low resistivity body protrudes 


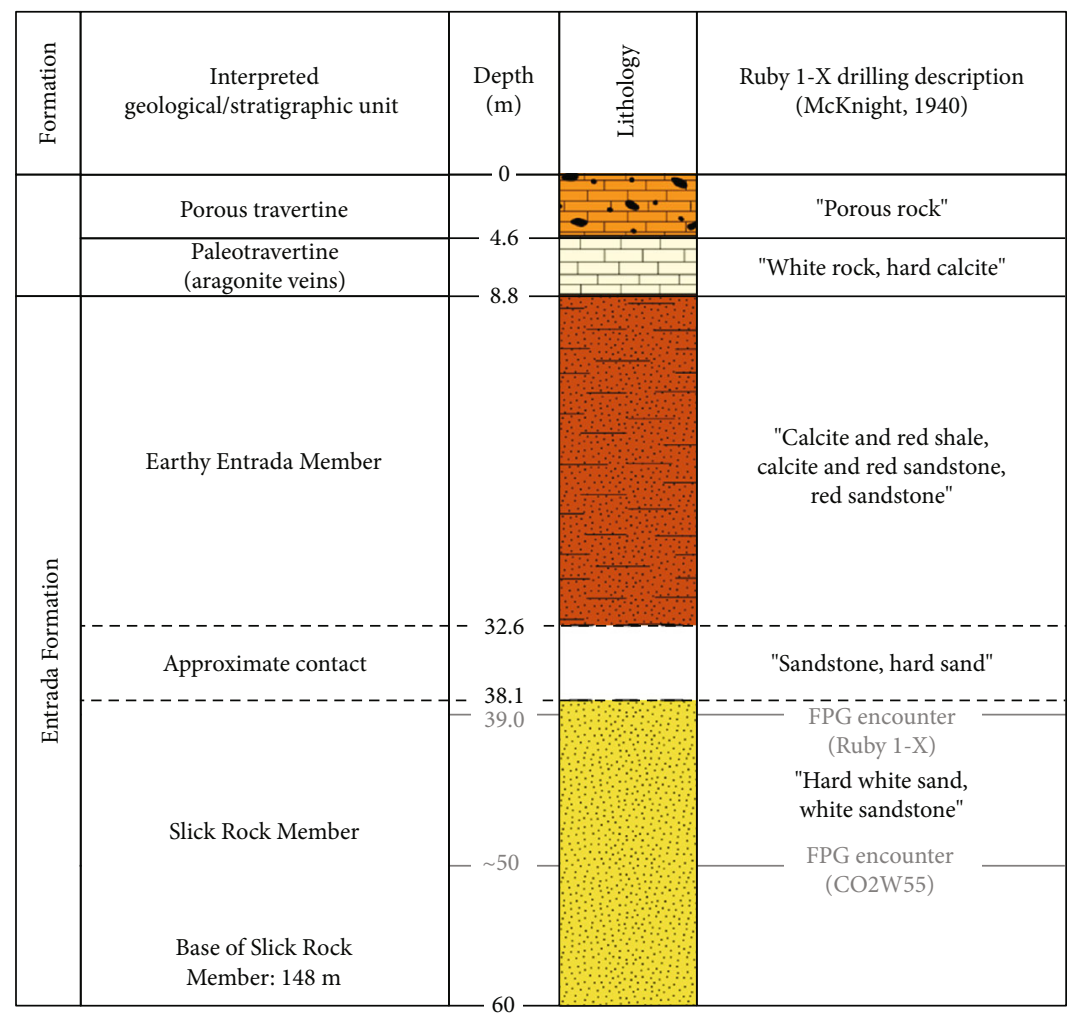

FIGURE 4: Crystal Geyser borehole log of interpreted geologic units to $60 \mathrm{~m}$ depth. Crystal Geyser was drilled from 1935 to 1936 to a total depth of $801 \mathrm{~m}$ and was cased to at least $182 \mathrm{~m}[12,22]$. Lithology interpretations were based on descriptions from the Crystal Geyser (Ruby $1-\mathrm{X})$ driller's $\log$, corroborated with the CO2W55 log $[12,13]$. The depths of drilling encounters with free-phase gas (FPG) are indicated for the Ruby 1-X and CO2W55 drilling logs.

upwards into the paleotravertine (Figure 5(a)). This resistivity feature is in the same approximate location as the northern primary splay of the Little Grand Wash Fault [3] (Figure 3); therefore, it is interpreted to be the northern splay's fault zone. Evident on the tomogram, the paleotravertine thickness is reduced to less than one metre where it overlies the fault zone (Figure 5(a)). The Little Grand Wash Fault zone is comprised of a clay-rich gouge within a fault core, surrounded by a damage zone [3]. The damage zone contains entrained host rock and slip zones where a majority of fault displacement occurred [3]. The fault core's clay-rich lithology created an elevated erosion-resistant butte [3], which was later intruded/overlain by the paleotravertine. The fault zone butte is approximately $9 \mathrm{~m}$ in lateral thickness with a resistivity range of 140 to $440 \Omega \mathrm{m}$, considerably lower in resistivity than the overlying paleotravertine. Figure 6 shows an exposure of the northern Little Grand Wash Fault core, also draped by the paleotravertine, located $70 \mathrm{~m}$ east from the ERT transect (location indicated in Figure 3). The morphology of this outcrop closely resembles the coincident resistivity body within the tomogram (Figure 5(a)).

South of the fault zone, the Brushy Basin Member of the Morrison Formation likely comprises the hanging wall between the two primary fault splays, based on Dockrill and Shipton's [3] field mapping (Figures 1 and 3). The Brushy Basin Member shale has a moderate resistivity ranging from 80 to $160 \Omega \mathrm{m}$.
The Earthy Member is exposed beyond the northern edge of the modern travertine. In this area, the Earthy Member was partially covered by a layer of dry, loose colluvium, causing a thin veneer of elevated surface resistivities (Figure 5(a) and Figure S1). Overall, the Earthy Member has the lowest resistivity compared to other tomogram units, varying from 10 to $80 \Omega \mathrm{m}$. South of the exposed area, the unit is laterally continuous at depth (with consistent resistivity) beneath the travertine units until it is truncated at the fault zone (Figure 5(a)).

A wide, anomalously high resistivity body within the Slick Rock Member is observed immediately south of Crystal Geyser's conduit (Figures 5(a) and 5(b)). The anomalous resistivities vary from 60 to $240 \Omega \mathrm{m}$, higher than the surrounding Slick Rock Member, which varies from 20 to $60 \Omega \mathrm{m}$ (Figure 5(a); Table 1). According to Archie's Law Equation, a porous medium with a relatively low water saturation $\left(S_{\mathrm{w}}\right)$ (or elevated FPG saturation $\left(S_{\mathrm{g}}\right)$ ) will have an elevated bulk resistivity (Equation (3); see Section 2.1.3). Consequently, the resistivity anomaly was interpreted as a FPG plume housed within the transmissive Slick Rock Member, with the Earthy Entrada Member acting as a caprock.

The Slick Rock Member demonstrates uniform bleaching due to $\mathrm{CO}_{2}$ invasion as a consequence of its elevated permeability (see Section 3.1) $[13,26]$. In contrast, the overlying red-brown Earthy Member is largely unbleached, indicating that it acted as a seal/caprock for buoyant $\mathrm{CO}_{2}$ - 

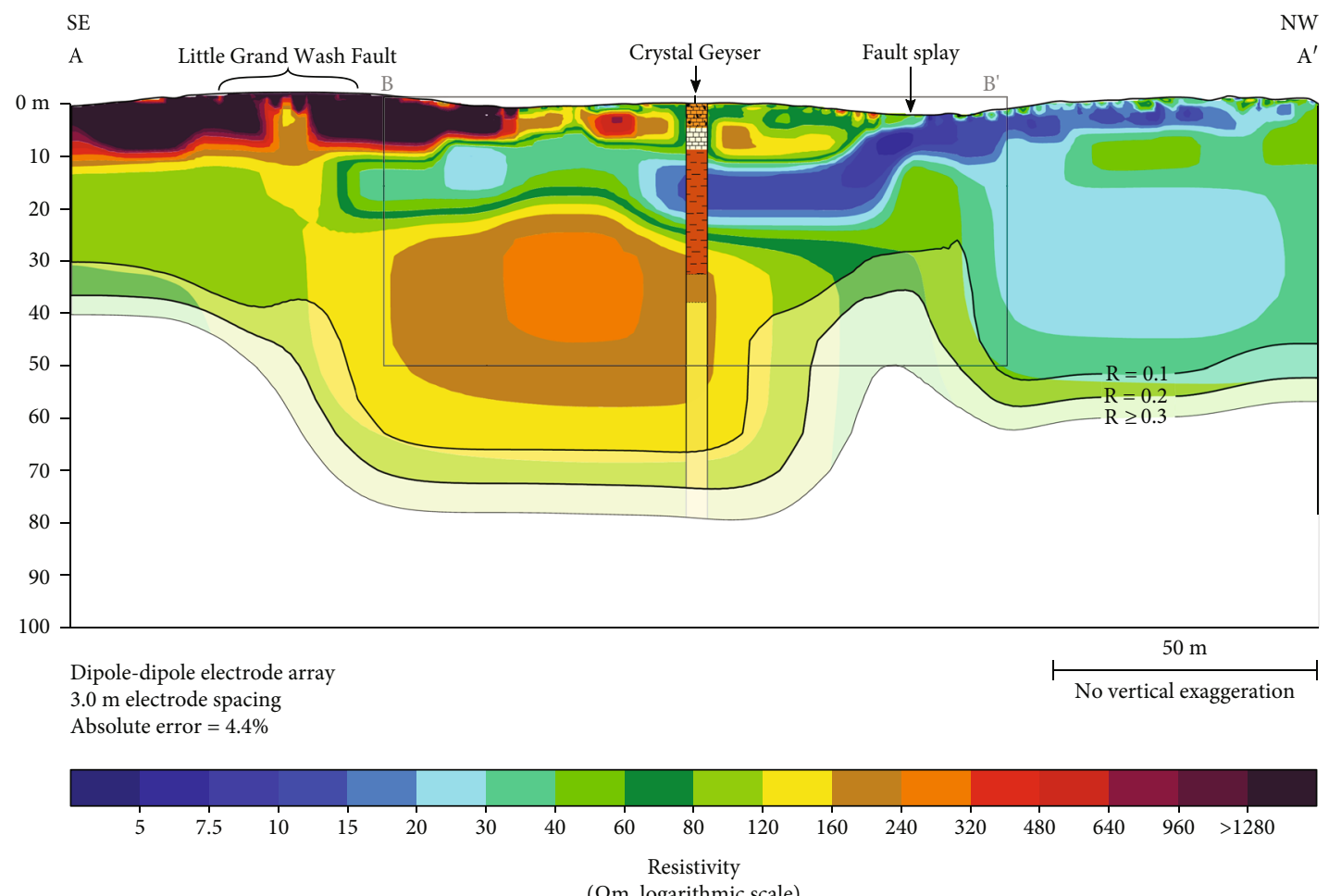

$(\Omega \mathrm{m}$, logarithmic scale)

(a)

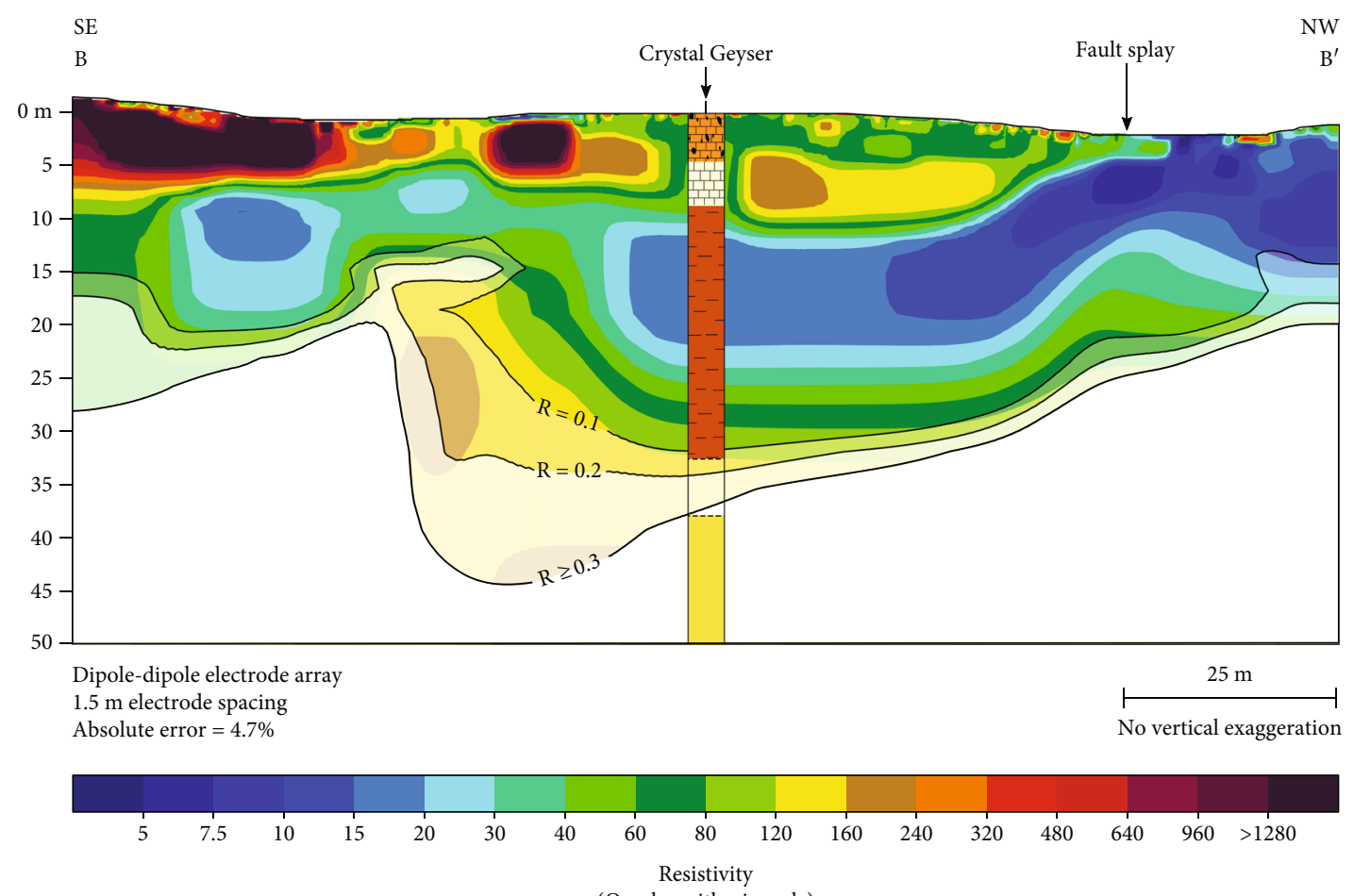

$(\Omega \mathrm{m}$, logarithmic scale)

(b)

Figure 5: Resistivity tomograms of transects $A-A^{\prime}$ (a) and $B-B^{\prime}$ (b) shown in Figure 3. Electrode spacings of 3.0 (a) and $1.5 \mathrm{~m}$ (b) were used for surveys, resulting in total survey lengths of 240 and $120 \mathrm{~m}$, respectively. The interpreted borehole log of Figure 4 is overlain onto the tomograms. All tomograms used a dipole-dipole electrode array, and all data were collected while Crystal Geyser was in the noneruptive period. The absolute errors of the fourth iteration are indicated. The depth datum is the ground surface at Crystal Geyser (depth $=0 \mathrm{~m})$. A DOI index $(R)<0.1$ to 0.2 indicates reliable areas of an image that are well constrained by the data. The area of (b) is indicated in (a) with a grey box. 
TABLE 1: Summary of resistivity ranges and tomogram-estimated vertical thicknesses for interpreted tomogram units. FPG: freephase gas. Resistivity ranges are the $5^{\text {th }}$ and $95^{\text {th }}$ percentile resistivities for each unit.

\begin{tabular}{lcc}
\hline Geological unit & $\begin{array}{c}\text { Resistivity range } \\
(\Omega \mathrm{m})\end{array}$ & $\begin{array}{c}\text { Apparent vertical } \\
\text { thickness }(\mathrm{m})\end{array}$ \\
\hline Paleotravertine & 130 to 4000 & $<1$ to 10 \\
Porous travertine & 50 to 180 & $<1$ to 5 \\
Fault zone & 140 to 440 & - \\
Earthy Member & 10 to 80 & 12 to 16 \\
Slick Rock Member & 20 to 240 & - \\
FPG plume & 60 to 240 & 30 to 40 \\
FPG absent & 20 to 60 & - \\
Brushy Basin Member & 80 to 160 & - \\
\hline
\end{tabular}

charged paleofluids [26]. Outcrop permeability measurements show that the Earthy Member has one to three magnitudes lower permeability than the Slick Rock Member because of comparatively higher silt content (and overall finer grain size), carbonate cement, and grain clay coatings [26]. Capillary barriers at the base of and within the Earthy Member presumably cause lateral spreading of FPG, e.g., $[1,5,9]$, leading to a present-day accumulation of FPG within the Slick Rock Member.

The interpreted FPG plume is approximately $70 \mathrm{~m}$ wide and is capped near the base of the Earthy Member (Figure 5(a)). A sharp downwards increase in resistivity occurs at 20 to $25 \mathrm{~m}$ below Crystal Geyser. However, this resistivity transition is several metres above the suspected basal contact of the Earthy Member (32.6 to $38.1 \mathrm{~m}$; Figures 4 and 5(a) and $5(\mathrm{~b})$ ), possibly because buoyant FPG is partially penetrating the base of the caprock, e.g., $[13,26]$.

With increasing depth, elevated resistivities within the anomaly return to lower values at 45 to $55 \mathrm{~m}$. The large vertical width of basal resistivity transition is likely caused by a combination of decreasing image resolution with depth and inversion smoothing. In addition, given the dynamic subsurface conditions associated with variable gas discharge from the geyser (over the duration of a survey), the FPG plume boundary may not be sharp, and there may be a gradational zone of FPG saturation. The DOI index $(R)$ values are less than 0.1 within the entire anomaly and basal transition zone (45 to $55 \mathrm{~m}$, Figure 5(a)). These low $R$ values indicate that the recovered resistivities are appropriately constrained by the field data and are repeatable. In contrast, resistivities located in areas where $R>0.1$ to 0.2 indicate that the geophysical data are becoming insensitive or unrepresentative of subsurface physical properties [17]. In Figure 5, areas with low sensitivity are shaded in white, increasing in opacity with increasing $R$ values. It was interpreted that the base of the FPG plume, or a FPG-groundwater interface, was imaged. The location of the interpreted interface was between 45 and $55 \mathrm{~m}$.

The existence of a subsurface FPG plume within the Slick Rock Member is consistent with the drilling observations of CO2W55. Kampman et al. [13] encountered a pocket of pressurized FPG at a coincident depth of approx- imately $50 \mathrm{~m}$ within the Slick Rock Member (depth indicated in Figure 4). Similarly, the FPG pocket in CO2W55 was overlain by siltstone layers of the Earthy Member, which were deemed sufficient in sealing the upward migration of buoyant FPG [13]. Also, a "show" of FPG was observed in the Ruby 1-X drilling $\log$ at a similar depth of $39 \mathrm{~m}$ (Figure 4) [12]. Considering the similarities in structural/stratigraphic orientation and proximity between Crystal Geyser and CO2W55 (285 m apart; Figure 1), it is possible that the accumulation of FPG is laterally continuous between the two locations or a discrete accumulation of FPG occurs near Crystal Geyser. Furthermore, from the mapping of other studies $[3,13]$, there is no fault displacement (which could cause changes in resistivity) at the northern margin of the interpreted gas plume. At the nearby Salt Wash Graben, exposed sections of thick cross-bedded sandstones of the Slick Rock Member are laterally continuous over $\mathrm{km}$-scale distances [26]. Therefore, it is unlikely that fault slip surfaces or lateral lithofacies changes caused the elevated resistivity observed within the Slick Rock Member.

The juxtaposition of the Little Grand Wash Fault against the dipping beds of the Green River Anticline suggests that migration of free-phase $\mathrm{CO}_{2}$ occurs mainly in an up-dip direction until laterally impeded by the fault. As the plume forms, buoyant FPG will tend to flow in the up-dip direction [5] of the Earthy Member caprock (i.e., southwards). The subvertical clay-rich fault core is recognized as a laterally sealing surface, preventing the FPG plume from escaping across the fault and into the hanging wall $[3,16,36]$. Therefore, the gas trap is sealed laterally (by the fault and limbs of the fold) and at the top (by the Earthy Member), causing FPG to accumulate. This interpretation is similar to previous numerical modelling studies $[26,28,29]$ that modelled the Little Grand Wash Fault as a free-phase $\mathrm{CO}_{2}$ gas source and the resulting up-dip migration and trapping of FPG against faults with low lateral permeability (i.e., the Salt Wash Graben or Little Grand Wash Fault).

3.3. Comparisons with Archie's Law Equation Calculated Resistivities. Separate estimates for bulk resistivity $\left(\rho_{\mathrm{b}}\right)$ using Equation (3) were conducted to evaluate the plausibility that the elevated tomogram resistivity values indicate a FPG plume within the Slick Rock Member (see Materials and Methods, Section 2.1.3). Outcrop porosity values of two lithofacies of the Slick Rock Member, measured by Newell et al. [26], were used in our calculations. In their numerical modelling studies, they used a measured porosity $(\phi)$ of 0.25 and 0.15 for the aeolian dune (cross-bedded sandstone) and interdune lithofacies (massive sandstone), respectively [26]. Previous studies have shown that Entrada Formation groundwater contributes a substantial proportion to geyser effluent $[13,21]$. Consequently, it was assumed that the groundwater conductivity within Crystal Geyser is similar to groundwater in the Slick Rock Member (the aquifer unit of the Entrada Formation, Figure 2). In Equation (3), a water electrical conductivity $\left(\sigma_{\mathrm{w}}\right)$ of $15.6 \mathrm{mS} / \mathrm{cm}$ was used, which was the mean value of continuous transducer measurements during Crystal Geyser's noneruptive period (Figure S6). To illustrate the relationship of increasing FPG saturation $\left(S_{\mathrm{g}}\right)$ 


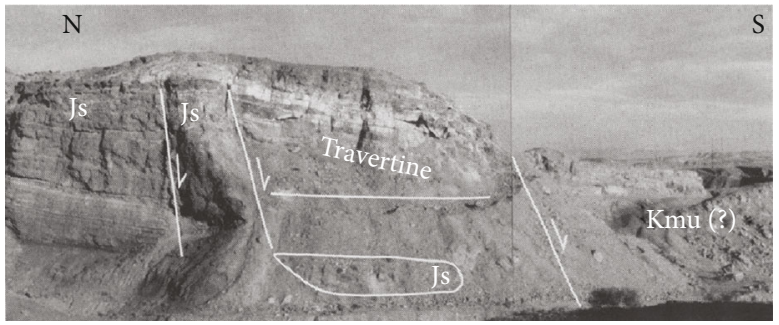

(a)

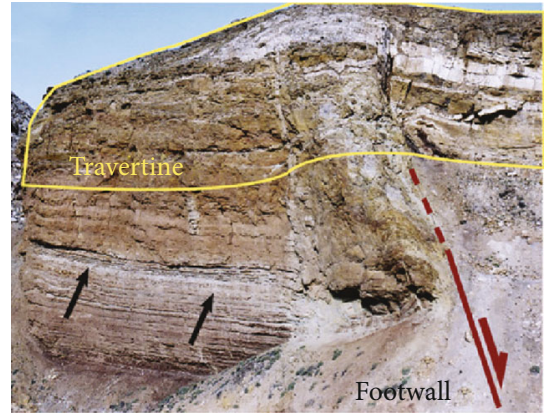

(b)

Figure 6: Photographs of vertical exposures of the northern and southern primary faults and surrounding damage zone of the Little Grand Wash Fault. The location of these photographs is indicated in Figure 3. (a) A photo of the primary fault splays of the Little Grand Wash Fault. The fault core is the narrow feature enclosed by two fault surfaces. Js: Jurassic Summerville Formation; Kmu: Cretaceous Mancos Shale (from Shipton et al. [14], Figure 5(a)). (b) Closeup of the clay-rich fault core and surrounding damage zone of the northern fault splay. The elevated erosion-resistant fault core is intruded/draped by the paleotravertine (from Dockrill and Shipton [3], Figure 5(d)).

on the resistivity of the Slick Rock Member, $S_{\mathrm{g}}$ was varied from 0 to 0.8 in Equation (3). A residual liquid saturation of $S_{\mathrm{w}}=0.2$ (i.e., $S_{\mathrm{g}}=0.8$ ) was used to represent gas saturated conditions [29]. Figure 7 compares the calculated resistivities to the tomogram.

As the pore space is occupied by more gas, both the aeolian dune and damp interdune resistivities increase from a magnitude of $10^{1}$ to $10^{2} \Omega \mathrm{m}$ (Figure 7). Compared to the aeolian dune facies, the damp interdune facies resistivity increases more steeply at high $S_{\mathrm{g}}$ because of lower porosity. The shaded areas (red and grey) indicate the range of tomogram resistivity values within and outside the FPG plume's interpreted boundaries (Figure 7; Table 1). Overall, the estimated one-order-ofmagnitude changes in calculated resistivities between plume and nonplume conditions are consistent with the interpretation of the FPG plume within the tomograms.

3.4. Subsurface Conceptual Model. Adapted from the $3.0 \mathrm{~m}$ electrode spacing tomogram (Figure 5(a)), a conceptual cross-section of the interpreted geological units and FPG distribution (from Section 3.2) is shown in Figure 8. The figure illustrates the location and depth of the FPG plume and gas migration pathways. During plume formation, FPG is supplied from Crystal Geyser's conduit or the Little Grand Wash Fault (red arrows in Figure 8). The fracture network (within the damage zone) of the Little Grand Wash Fault and Crystal Geyser are primary vertical conduits of free-phase $\mathrm{CO}_{2}$ gas in the area $[3,16]$. FPG is redirected from the geyser conduit into the gas trap or accumulates adjacent to the intersection of the fault and the Earthy Member caprock (Figure 8). Simultaneously, the fault fracture network and Crystal Geyser act as FPG pathways, transporting gas from the plume to the surface (Figure 8). The conceptual model assumes that the casing integrity is compromised, allowing transfer of fluids between Crystal Geyser's conduit and the Entrada Formation. With the submersible camera, the geyser casing was observed to be completely corroded/destroyed and the top of a cave began at a depth of $3.3 \mathrm{~m}$ (Figures S4 and S8). The casing could be similarly compromised at greater depth within the Entrada Formation, allowing for the transfer of

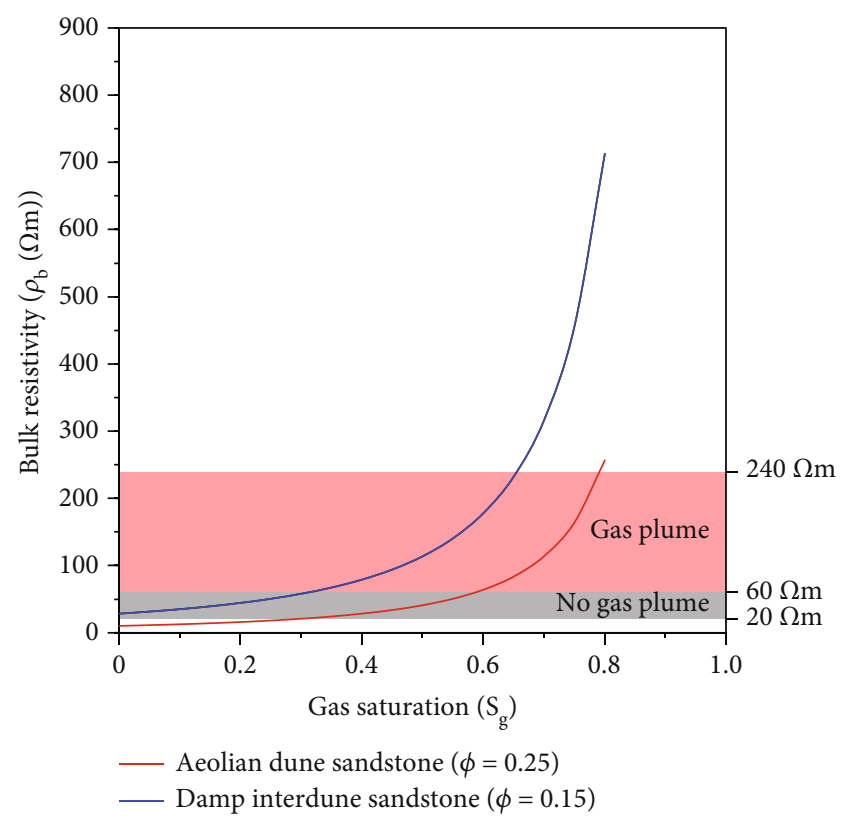

FIgURE 7: Archie's Law Equation calculated bulk resistivities $\left(\rho_{\mathrm{b}}\right)$ for lithofacies of the Slick Rock Member [26]. FPG saturation $\left(S_{\mathrm{g}}\right)$ was varied from 0 to a maximum value of 0.8 . The groundwater conductivity value $\left(\sigma_{\mathrm{w}}\right)$ used in the calculations was $15.6 \mathrm{mS} / \mathrm{cm}$. The shaded areas indicate the tomogram resistivity ranges $\left(5^{\text {th }}\right.$ to $95^{\text {th }}$ percentile) for the interpreted boundaries of the free-phase gas plume (Table 1).

fluids between the aquifer and geyser conduit (bidirectional arrow in Figure 8).

To evaluate the spatial association between the interpreted subsurface plume and surface $\mathrm{CO}_{2}$ leakage, surface soil free-phase $\mathrm{CO}_{2}$ gas flux measurements from Jung et al. [16] were overlain onto the ground surface of Figure 8. Elevated $\mathrm{CO}_{2}$ fluxes, typically from 20 to $500 \mathrm{gm}^{-2} \mathrm{~d}^{-1}$ (to a maximum of 500 to $1500 \mathrm{gm}^{-2} \mathrm{~d}^{-1}$ ), were measured at/near the northern fault trace and in the area between the fault trace and Crystal Geyser (yellow and orange points, Figure 8) [16]. The highest measured fluxes of the study were 


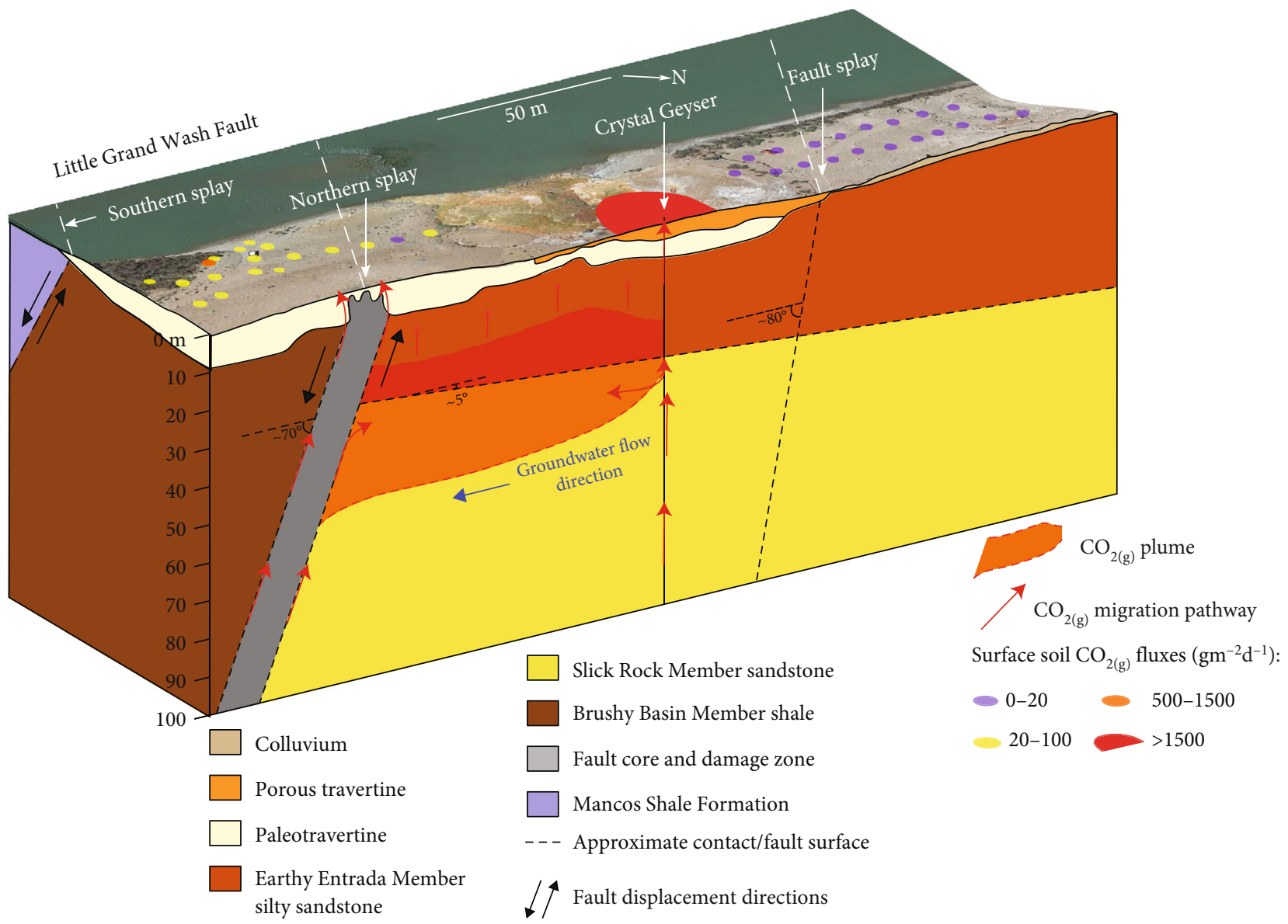

Figure 8: Conceptual model adapted from Figure 5(a) of interpreted subsurface geology with free-phase gas (FPG) distribution and migration. The $\mathrm{CO}_{2(\mathrm{~g})}$ flux measurements by Jung et al. [16] are overlain onto the surface. The damage zone of the Little Grand Wash Fault (northern primary splay) and Crystal Geyser supply FPG to the gas trap beneath the Earthy Member silty sandstone (red arrows within the plume). The gas trap is bounded laterally by the fault and geyser conduit (N-S) and by the limbs of the Green River Anticline (W-E). The fault and Crystal Geyser are the predominant FPG pathways to the surface (red arrows leading to the ground surface). Between the Crystal Geyser and the fault, free gas migrates upwards up and around discrete capillary barriers within the Earthy Entrada Member (small red arrows above plume). Figure S7 is an alternate version of Figure 8 with the tomogram image.

emitted from and within $5 \mathrm{~m}$ of Crystal Geyser (average of $9600 \mathrm{gm}^{-2} \mathrm{~d}^{-1}[16]$; indicated with the red area around Crystal Geyser, Figure 8). North of the modern travertine, FPG fluxes were within the range of background $\mathrm{CO}_{2}$ flux values (0 to $20 \mathrm{gm}^{-2} \mathrm{~d}^{-1}$ [16]; purple points, Figure 8). Furthermore, FPG flux measurements from the northern fault trace and Crystal Geyser were interpreted to be the most advective transport dominant, relative to the more diffusive-dominant background fluxes and fluxes at other fault traces [16]. The association with advective transport suggests that the northern fault fracture network and the geyser conduit are the primary pathways for free $\mathrm{CO}_{2}$ in the Little Grand Wash Fault zone [16]. Figure 8 suggests that the location of the FPG plume (and high resistivity anomalies) was consistent with the distribution of elevated surface free-phase $\mathrm{CO}_{2}$ gas fluxes and the locations of the predominant gas pathways. The high permeability conduits bound the zone of elevated FPG saturation, suggesting that the further lateral spreading of gas would be diverted into the fault fracture network and/or the geyser conduit. Therefore, anomalously high resistivities and associated elevated soil fluxes were not observed north of the geyser conduit (Figures 5(a) and 8).

Between the northern fault and Crystal Geyser, a relatively low flux of FPG presumably migrates upwards between discrete capillary barriers within the Earthy Entrada Member (red arrows within the Earthy Member in Figure 8). The Earthy Member sedimentary structure contains irregular lenses of sandstone separated by discontinuous beds of silt and clay [26]. FPG migrates upwards and around the fine-grained beds (or "baffles") within the higher permeability sandstone $[5,9]$.

\section{Conclusions}

Crystal Geyser, an unsealed and partially cased well resulting from a failed drilling project, transports stray $\mathrm{CO}_{2}$ gas to the shallow subsurface. Previous studies had inferred or modelled surrounding subsurface $\mathrm{CO}_{2}$ free-phase gas (FPG) accumulations; however, the actual location and dimensions remained 
unclear. This study applies the current understanding of buoyant FPG migration to characterize the distribution and behaviour of FPG surrounding a compromised borehole, fault network, and low-permeability siltstone.

By interpreting electrical resistivity images with previous drilling records and field mapping, the two-dimensional extent of a subsurface FPG plume (i.e., a zone of elevated FPG fraction in the pore space) was identified within the Entrada Formation, immediately south of Crystal Geyser. The interpreted FPG plume was housed within the Slick Rock Member sandstone, with the relatively low permeability Earthy Member silty sandstone/siltstone acting as the seal. The roles of these stratigraphic units as a reservoir and seal were evidenced by preferential sandstone bleaching (due to relative differences in permeability [26]) and drilling encounters with pressurized FPG $[12,13]$. The interpreted FPG plume is approximately $70 \mathrm{~m}$ wide, laterally bounded by the northern splay of the Little Grand Wash Fault and the conduit of Crystal Geyser. The plume base (i.e., a FPG-groundwater interface) was imaged at 45 to $55 \mathrm{~m}$ depth.

The FPG plume was identified from an anomalously high resistivity zone within the tomogram images that was not caused by lateral lithofacies changes or fault displacement. Depth of investigation analysis suggests that the inverted resistivities within and surrounding the anomaly are reliable. It is plausible that a FPG plume caused the tomogram anomaly because bulk resistivity estimates of the Slick Rock Member containing elevated gas saturation were similar in magnitude compared to the anomalous tomogram resistivities.

This study presents conceptual mechanisms of FPG migration that sustain the gas plume. FPG accumulates by up-dip lateral spreading alongside fine-grained capillary barriers at the bottom and within the Earthy Member. The fault network of the Northern Little Grand Wash Fault splay and the conduit of Crystal Geyser act as vertical preferential FPG pathways that act both as a source and release for the gas plume. The role of these features as high vertical permeability pathways is supported because the lateral margins of the FPG plume (i.e., the zone of anomalously high resistivities) coincide with the locations of the fault network and geyser conduit. Furthermore, the imaged locations of the FPG plume and high vertical permeability pathways are similar to locations of elevated surface $\mathrm{CO}_{2}$ flux measurements by Jung et al. [16].

\section{Data Availability}

Data are available from the corresponding author by reasonable request.

\section{Disclosure}

An unpublished version of this manuscript was submitted as a poster and presentation to Geoconvention 2021 prior to publication in Geofluids.

\section{Conflicts of Interest}

The authors declare that there is no conflict of interest regarding the publication of this paper.

\section{Acknowledgments}

This research would not be possible without the generosity and technical support of Landon Woods, the undergraduate thesis work of Race Houston, and the Town of Green River (Utah) for kindly giving us access to conduct research on their property. This study was supported by the University of Calgary Faculty of Science Grand Challenges Fund (Ryan) and an Alberta Graduate Excellence Scholarship (Lagasca).

\section{Supplementary Materials}

Figure S1: study site photo of the $A-A^{\prime}$ ERT line, looking south. The $73^{\text {rd }}$ to $76^{\text {th }}$ electrode locations are indicated, with a $3.0 \mathrm{~m}$ electrode spacing (80 electrodes in total). The interpreted stratigraphic units and travertines are indicated with dashed lines. Figure S2: study site photo of the $A-A^{\prime}$ ERT line, looking north. This photo was taken at the location of the northern primary splay of the Little Grand Wash Fault. The $18^{\text {th }}$ to $21^{\text {st }}$ electrode locations are indicated, with a $3.0 \mathrm{~m}$ electrode spacing (80 electrodes in total). The interpreted stratigraphic units and travertines are indicated with dashed lines. Figure S3: study site photo of the exposed geological units immediately east of Crystal Geyser. The interpreted stratigraphic units and travertines are indicated with dashed lines $[3,14]$. The assumed location of a secondary fault splay (identified by Kampman et al. [13]) intersects the stratigraphic units in this photo. There is no observable displacement at the exposed contact between the Earthy Member and Curtis Formation. Figure S4: stitched image of a rubble blockage at the base of a cave below Crystal Geyser. The geyser casing was completely corroded/destroyed beginning at a depth of $3.3 \mathrm{~m}$ within the travertines. The cave was obstructed by a rubble blockage at $8.6 \mathrm{~m}$. Using the $1^{\prime \prime}$ $(2.54 \mathrm{~cm})$ PVC pipe in the image as a reference, there is a cave at least $1.8 \mathrm{~m}$ by 0.7 wide and $5.3 \mathrm{~m}$ long at the depth of the blockage. The cave may be more extensive in the lateral dimensions. Figure S5: supplementary resistivity tomograms of transects $A-A^{\prime}$ (A) and $B-B^{\prime}$ (B-D) in Figure 5. Electrode spacings of $3.0(\mathrm{~A})$ and $1.5 \mathrm{~m}(\mathrm{~B}-\mathrm{D})$ were used for surveys, resulting in total survey lengths of 240 and $120 \mathrm{~m}$, respectively. The interpreted borehole log of Figure 4 is overlain onto the tomograms. A, C, and D used a gradient electrode array, whereas B used a dipole-dipole array. Data were collected while Crystal Geyser was in the noneruptive phase. The absolute errors of the fourth iteration are indicated. The depth datum is the ground surface at Crystal Geyser (depth $=0 \mathrm{~m}$ ). A DOI index $(R)<0.1$ to 0.2 indicates reliable areas of an image that are well constrained by the data. The area of B-D is indicated in A with a grey box. Figure S6: continuous data of level, electrical conductivity, and temperature for the transducer that was installed at $8.6 \mathrm{~m}$ depth within Crystal Geyser. $X$-axis ticks are midnight each day. Erroneous data was removed on February 17 (data gap). The average water electrical conductivity $\left(\sigma_{\mathrm{w}}\right)$ for the available data within the periods shaded in grey was 
$15.6 \mathrm{mS} / \mathrm{cm}$, which was used in Archie's Law calculated resistivities. The survey duration of tomograms in Figures 5(a) and 5(b) and Figures S5A-S5D is indicated as blue bars. Crystal Geyser eruption behaviour changes are indicated with dashed grey lines: R: recharge; $\mathrm{mEP}$ : minor eruption period; Ae: aftershock eruptions; MEP: major eruption period (eruption classification from [21]). Figure S7: an alternate version of Figure 8; conceptual model of interpreted subsurface geology with freephase gas distribution and migration overlain onto tomogram from Figure 6(a). Figure S8: diagram of the shallow subsurface $(<10 \mathrm{~m})$ at Crystal Geyser with the observed cave, including interpreted lithologies and the transducer depth (Figure 4 and Figure S5). The cave may be more extensive in the lateral dimensions. The lowest estimated water level (from transducer measurements) was 2.4 metres below ground surface (mbgs), measured during geyser recharge. (Supplementary Materials)

\section{References}

[1] L. J. Molofsky, J. A. Connor, C. J. C. Van De Ven et al., “A review of physical, chemical, and hydrogeologic characteristics of stray gas migration: implications for investigation and remediation," Science of the Total Environment, vol. 779, 2021.

[2] R. E. Jackson, A. W. Gorody, B. Mayer, J. W. Roy, M. C. Ryan, and D. R. van Stempvoort, "Groundwater protection and unconventional gas extraction: the critical need for fieldbased hydrogeological research," Groundwater, vol. 51, no. 4, pp. 488-510, 2013.

[3] B. Dockrill and Z. K. Shipton, "Structural controls on leakage from a natural $\mathrm{CO}_{2}$ geologic storage site: Central Utah, U.S.A.," Journal of Structural Geology, vol. 32, no. 11, pp. 1768-1782, 2010.

[4] E. R. Siirila, A. K. Navarre-Sitchler, R. M. Maxwell, and J. E. McCray, "A quantitative methodology to assess the risks to human health from $\mathrm{CO}_{2}$ leakage into groundwater," Advances in Water Resources, vol. 36, pp. 146-164, 2012.

[5] A. W. Woods and S. Norris, "Dispersion and dissolution of a buoyancy driven gas plume in a layered permeable rock," Water Resources Research, vol. 52, pp. 2682-2697, 2016.

[6] A. G. Cahill, C. M. Steelman, O. Forde et al., "Mobility and persistence of methane in groundwater in a controlledrelease field experiment," Nature Geoscience, vol. 10, no. 4, pp. 289-294, 2017.

[7] C. M. Steelman, D. R. Klazinga, A. G. Cahill, A. L. Endres, and B. L. Parker, "Monitoring the evolution and migration of a methane gas plume in an unconfined sandy aquifer using time-lapse GPR and ERT," Journal of Contaminant Hydrology, vol. 205, pp. 12-24, 2017.

[8] T. A. Cary, Time-lapse electrical resistivity imaging of methane gas migration in a shallow confined aquifer, [M.S. thesis], University of Calgary, Calgary, AB, 2019.

[9] C. J. C. Van De Ven and K. G. Mumford, "Intermediate-scale laboratory investigation of stray gas migration impacts: methane source architecture and dissolution," Enviornmental Science and Technology, vol. 54, no. 10, pp. 6299-6307, 2020.

[10] L. Slater, X. Comas, D. N. Ntarlagiannis, and M. R. Moulik, "Resistivity-based monitoring of biogenic gases in peat soils," Water Resources Research, vol. 43, no. 10, pp. 1-13, 2007.

[11] N. Terry, L. Slater, X. Comas, A. S. Reeve, K. V. R. Schafer, and $\mathrm{Z}$. $\mathrm{Yu}$, "Free phase gas processes in a northern peatland inferred from autonomous field-scale resistivity imaging," Water Resources Research, vol. 52, no. 4, pp. 2996-3018, 2016.

[12] E. T. McKnight, "Geology of area between Green and Colorado Rivers Grand and San Juan Counties Utah," Geological Survey Bulletin, vol. 908, pp. 143-144, 1940.

[13] N. Kampman, M. J. Bickle, A. Maskell et al., "Drilling and sampling a natural $\mathrm{CO}_{2}$ reservoir: implications for fluid flow and $\mathrm{CO}_{2}$-fluid-rock reactions during $\mathrm{CO}_{2}$ migration through the overburden," Chemical Geology, vol. 369, pp. 51-82, 2014.

[14] Z. K. Shipton, J. P. Evans, D. Kirschner, P. T. Kolesar, A. P. Williams, and J. Heath, "Analysis of $\mathrm{CO}_{2}$ leakage through 'low-permeability' faults from natural reservoirs in the Colorado Plateau, east-central Utah," Geological Society, London, Special Publications, vol. 233, no. 1, pp. 43-58, 2004.

[15] H. H. Doelling, P. A. Kuehne, G. C. Willis, and J. B. Ehler, Geologic map of the San Rafael Desert 30' x 60' quadrangle, Emery and Grand Counties, Utah (map 267DM), Utah Geological Survey, Salt Lake City, UT, USA, 2015, https://digitallibrary .utah.gov/awweb/main.jsp?flag=collection\&smd=1\&cl=all_ lib\&lb_document_id=77901\&tm=1603994178168.

[16] N. Jung, W. S. Han, Z. T. Watson, J. P. Graham, and K. Kim, "Fault-controlled $\mathrm{CO}_{2}$ leakage from natural reservoirs in the Colorado Plateau, East-Central Utah," Earth and Planetary Science Letters, vol. 403, pp. 358-367, 2014.

[17] D. W. Oldenburg and Y. Li, "Estimating depth of investigation in dc resistivity and IP surveys," Geophysics, vol. 64, no. 2, pp. 403-416, 1999.

[18] S. Falzone, J. Robinson, and L. Slater, "Characterization and monitoring of porous media with electrical imaging: a review," Transport in Porous Media, vol. 130, no. 1, pp. 251-276, 2019.

[19] W. S. Han, M. Lu, B. J. McPherson et al., "Characteristics of $\mathrm{CO}_{2}$-driven cold-water geyser, Crystal Geyser in Utah: experimental observation and mechanism analyses," Geofluids, vol. 13, no. 3, p. 297, 2013.

[20] R. L. Powell, "Crystal Geyser, Green River, Utah: a summary of observations from 1972-2008," The GOSA Transactions, vol. 12, pp. 138-151, 2012.

[21] W. S. Han, Z. T. Watson, N. Kampman, T. Grundl, J. P. Graham, and E. H. Keating, "Periodic changes in effluent chemistry at cold-water geyser: Crystal Geyser in Utah," Journal of Hydrology, vol. 550, pp. 54-64, 2017.

[22] Anonymous, Progress Made at Utah Southern and Ruby Oil Well Tests, The Times-Independent, Moab, Utah, 1936.

[23] A. J. Probst, B. Ladd, J. K. Jarett et al., "Differential depth distribution of microbial function and putative symbionts through sediment-hosted aquifers in the deep terrestrial subsurface," Nature Microbiology, vol. 3, no. 3, pp. 328-336, 2018.

[24] N. Kampman, N. M. Burnside, Z. K. Shipton et al., "Pulses of carbon dioxide emissions from intracrustal faults following climatic warming," Nature Geoscience, vol. 5, no. 5, pp. 352-358, 2012.

[25] N. Kampman, A. Busch, P. Bertier et al., "Observational evidence confirms modelling of the long-term integrity of $\mathrm{CO}_{2}$-reservoir caprocks," Nature Communications, vol. 7, no. 1, 2016.

[26] A. J. Newell, A. Pourmalek, A. S. Butcher, and S. M. Shariatipour, "The importance of lithofacies control on fluid migration in heterogeneous aeolian formations for geological $\mathrm{CO}_{2}$ storage: lessons from observational evidence and modelling of bleached palaeoreservoirs at Salt Wash Graben, Utah," International Journal of Greenhouse Gas Control, vol. 91, 2019. 
[27] Z. T. Watson, W. S. Han, E. H. Keating, N. Jung, and M. Lu, "Eruption dynamics of $\mathrm{CO}_{2}$-driven cold-water geysers: Crystal, Tenmile geysers in Utah and Chimayo geyser in New Mexico," Earth and Planetary Science Letters, vol. 408, pp. 272-284, 2014.

[28] N. Jung, W. S. Han, K. Han, and E. Park, "Regional-scale advective, diffusive, and eruptive dynamics of $\mathrm{CO}_{2}$ and brine leakage through faults and wellbores," Journal of Geophysical Research: Solid Earth, vol. 120, no. 5, pp. 3003-3025, 2015.

[29] G. Han, W. S. Han, K.-Y. Kim, J. G. Park, J. Piao, and T. K. Yun, "Roles of fault structures and regional formations on $\mathrm{CO}_{2}$ migration and distribution in shallow saline aquifer in Green River, Utah,” Journal of hydrology, vol. 570, pp. 786801, 2019.

[30] J. A. Barth, Crystal Geyser, Utah: active travertine deposits of a cold-water carbon dioxide-driven geyser and related ancient deposits of the Little Grand Wash Fault, [M.S. thesis], University of Houston, Houston, TX, USA, 2012, https://uh-ir.tdl .org/handle/10657/ETD-UH-2012-08-509.

[31] Guideline Geo, “ABEM Terrameter LS 2 Resistivity Meter," 2021, April 2021, https://www.guidelinegeo.com/product/ abem-terrameter-ls-2/.

[32] M. H. Loke, "RES2DINVx64 ver. 4.09," 2019, December2019, https://www.geometrics.com/software/res2dinv/.

[33] L. Marescot, M. H. Loke, D. Chapellier, R. Delaloye, C. Lambiel, and E. Reynard, "Assessing reliability of 2D resistivity imaging in mountain permafrost studies using the depth of investigation index method," Near Surface Geophysics, vol. 1, no. 2, pp. 57-67, 2003.

[34] Solinst, "LTC Levelogger Edge," 2021, April 2021, https://www .solinst.com/products/dataloggers-and-telemetry/3001levelogger-series/operating-instructions/user-guide/1introduction/1-1-9-ltc-levelogger-edge.php.

[35] Well-Vu, “Manual systems," 2021, April 2021, https://www .wellvu.com/manual-systems.

[36] V. F. Bense and M. A. Person, "Faults as conduit-barrier systems to fluid flow in siliciclastic sedimentary aquifers," Water Resources, vol. 42, no. 5, 2006. 